\title{
Does Internet and Computer "Addiction" Exist? Some Case Study Evidence
}

\author{
MARK GRIFFITHS, Ph.D.
}

\begin{abstract}
It has been alleged that social pathologies are beginning to surface in cyberspace (i.e., technological addictions). To date, there is very little empirical evidence that computing activities (i.e., internet use, hacking, programming) are addictive. Anecdotal evidence indicates that the typical "addict" is a teenager, usually male, with little or no social life, and little or no self-confidence. This article concentrates on five case studies of excessive computer usage. It is argued that of the five cases, only two of them describe "addicted" subjects. Addiction components criteria were used in the assessment. The excessive usage in the majority of cases was purely symptomatic and was highlighted how the subjects used the Internet/computer to counteract other deficiencies.
\end{abstract}

\section{INTRODUCTION}

$\mathbf{I}$ T HAS BEEN ALLEGED that social pathologies are beginning to surface in cyberspace (i.e., technological addictions). ${ }^{1,2}$ Technological addictions are operationally defined as nonchemical (behavioural) addictions that involve humanmachine interaction. They can either be passive (e.g., television) or active (e.g., computer games) and usually contain inducing and reinforcing features that may contribute to the promotion of addictive tendencies. ${ }^{3-5}$ This author's view is that technological addictions are a subset of behaviourial addictions ${ }^{6}$ and that behaviourial addictions feature the core components of addiction (i.e., salience, mood modification, tolerance, withdrawal, conflict and relapse). ${ }^{7}$ These core components are expanded upon.

\section{Salience}

This occurs when the particular activity becomes the most important activity in the per- son's life and dominates his or her thinking (preoccupations and cognitive distortions), feelings (cravings), and behaviour (deterioration of socialized behaviour). For instance, even if the person is not actually engaged in the behaviour, he or she will be thinking about the next opportunity to do so.

\section{Mood modification}

This refers to the subjective experiences that people report as a consequence of engaging in the particular activity and can be seen as a coping strategy (i.e., they experience an arousing "buzz" or a "high" or paradoxically tranquilizing feel of "escape" or "numbing").

\section{Tolerance}

This is the process whereby increasing amounts of the particular activity are required to achieve the former effects. For instance, a 
gambler may have to gradually have to increase the size of the bet to experience a euphoric effect that was initially obtained by a much smaller bet.

\section{Withdrawal symptoms}

These are the unpleasant feeling states and/or physical effects that occur when the particular activity is discontinued or suddenly reduced (e.g., the shakes, moodiness, irritability, etc.).

\section{Conflict}

This refers to the conflicts between the addict and those around them (interpersonal conflict) or from within the individuals themselves (intrapsychic conflict) that are concerned with the particular activity.

\section{Relapse}

This is the tendency for repeated reversions to earlier patterns of the particular activity to recur and for even the most extreme patterns typical of the height of the addiction to be quickly restored after many years of abstinence or control.

To date, there is very little empirical evidence that computing activities (i.e., internet use, hacking, programming) are addictive. Anecdotal evidence indicates that the typical "addict" is a teenager, usually male, with little or no social life and little or no self-confidence. ${ }^{8}$ However, recent work suggests there are individuals who do not fit this stereotype. ${ }^{9}$ This article concentrates on five case studies of excessive computer usage collected by the author over a period of 6 months. Each of the outlined cases has been given a pseudonym and a demographic description (i.e., age, gender, nationality, status). Information is also given about the origin and source of the case study. Each case is also followed by a brief commentary.

\section{GARY}

Demographic profile: 15-year-old British male (at school); source of account: author contacted by subject's mother who heard about au- thor's research on a national radio programme; and origin of data: written correspondence.

Gary is an only child and spends many hours on his home computer, averaging at least 3-4 hours a day in school term, with up to 5 or 6 hours or more a day at weekends. During the school holidays it increases even more, especially because he is on his own in the house whilst his parents are at work. Gary's mother describes him as "extremely good technically, very bright and very good at computer programming." His mother claims "he is computer mad, but not for computer games, rather for serious computing-programming etc." His General Certificate of Secondary Education homework has been increasingly suffering because of the time he spends on his computer. When he is not working on his computer, he watches television.

Gary suffers from neurofibromotosis, a condition that can produce severe behavioural problems to varying degrees. According to his mother, Gary has always had problems socially. He has had difficulty in making friends, difficulty in coping with teasing and minor bullying (usually of a verbal nature). His parents feel he views his computer as a "friend" and, therefore, tends to spend much of his time on the machine. Gary also suffers from an inferiority complex and lack of confidence when dealing with his peers. As a consequence, he gets very depressed. This condition worsened when he got his own computer. At the same time, his general behaviour worsened. He refused to do his normal household chores when requested, was generally awkward and difficult, and provoked confrontational situations between himself and other members of the family.

He spends time with the computer to the exclusion of family and friends. His parents had his general practitioner refer him to a psychiatrist for counselling and help. Whilst Gary viewed this as a possible "quick fix" for his problems, it was very slow progress. He is still getting the help of the local psychological services. His mother feels that much of his lack of confidence stems from the fact that he is content to spend his time in his room to the exclusion of others in his own world. She sees the problem as "a self-induced Catch 22 situation" in that he will never make friends whilst he 
spends time alone, but the action of spending time alone reduces his ability to deal with other people. Gary's own view is that he does not have a problem with his computer use and that he does not spend too much time on the computer. There is no doubt that this appears to be an unusual case and that Gary's excessive time spent on the computer appears to be symptomatic of other underlying problems.

\section{Commentary}

Gary appears to fit the stereotype of a computer addict in that he is a male teenager who appears to have little or no social life and little or no self-confidence. He appears to use the machine as an "electronic friend" - a behaviour that has been reported with other technological products such as video games ${ }^{10}$ and slot machines. ${ }^{3-5} \mathrm{He}$ appears to display all the core components of addiction and like many addicts, denies he has any kind of problem. His primary motivation for excessive use of his computer appears to be some sort of escapism into his own world where he can counteract his depression and forget about his social isolation and his medical condition (neurofibromotosis).

\section{JAMIE}

Demographic profile: 16-year-old British male (at college); source of account: Subject appeared on television programme (about Internet addiction) with author and continued correspondence; origin of data: face-to-face interview and written correspondence via the Internet.

Jamie is an only child and lives alone with his mother. There appears to be few problems in Jamie's family life although his mother divorced his father when Jamie was 3 years old. Jamie has no physical problems although he is very overweight. Jamie spends approximately 70 hours a week on his computer including 40 hours on the Internet. This includes two 12-hour sessions at the weekend. Only 3 hours a week is spent on work-related activities. Jamie's usual pattern is to log on between 2 p.m. and 4 p.m. in the afternoon and $\log$ off between 1 a.m. and 5 a.m. in the morning. He describes himself as "sci-fi mad" and spends "hours and hours" taking part in Usenet discussion groups about the television programme Star Trek (and its spin-offs). Although he had played computer games when he was younger, Jamie first used a computer properly when he was 14 years of age. He used the Internet for about 10 months before getting a modem. As a consequence of his excessive Internet use, the house telephone bills are large.

Jamie claims the Internet is the most important things in his life, and that he thinks about it even when he is not using it. He claims the Internet can change his mood-either calming him or exciting him. He gets withdrawal symptoms if he cannot get Internet access. When trying to cut down or quit, he finds the lure of cyberspace too strong to resist ("I get very irritable and I start to shake"). However, he does not view himself as an "addict."

Jamie says he has difficulty limiting or controlling the time both on and offline. Over a 2year period he has upgraded his computer 11 times. He says "I log on literally until I am physically unplugged by someone else . . . I can't work or live without it-my social and intellectual life are linked directly to it." If he's not connected-even for a short length of time, he worries he no longer knows "what is going on." Jamie's use of the Internet causes irregular sleeping patterns. It doesn't bother him that he has become nocturnal in order to use the Internet when the telephone charges are low. Occasionally he oversleeps and misses college because of his computer usage. He has tried to quit the internet-once giving up for 3 daysbut the pressure to $\log$ back on proved too great.

If Jamie was not online, he feels he would not use that time to meet people in real life ("I tend not to socialise much"). He has no friends outside of those he meets on Internet Relay Chat (IRC) and has no desire to make any. Jamie uses the Internet for a variety of different chat methods (e.g., IRC, Westwood Chat, as well as the Web and newgroups). Jamie claims he uses these services "to meet lots of people." He feels that the Internet has improved his level of knowledge and intends to enter an Internet-related field of employment. 


\section{Commentary}

Jamie-like the case of Gary above-appears to fit the stereotype of an internet addict in that he is a male teenager who appears to have little or no social life, little or no self-confidence, displays all the core components of addiction, and denies he has any kind of problem. However, Jamie claims to have "friends" although all of these are "net friendships." His passion for science-fiction echoes research carried out by Wolfson ${ }^{11}$ who found that obsessive fans of the television programme Star Trek use the Internet extensively. Jamie's primary motivation for using the Internet excessively is to socialise with other Internet users. It may be the case that Jamie feels comfortable in the text-based (non-face-to-face) world of the Internet because of his obesity.

\section{PANOS}

Demographic profile: 20-year old Greek male (at university); source of account: subject contacted author via an Internet discussion group; origin of data: Written correspondence via the Internet.

Panos has played on computer games since he was a small child. As an only child he got almost anything he wanted when he was younger, including all forms of electronic technology. He recalls that as a child he had a small computer on which he used to play games but used the computer for nothing else. Panos claims that at that particular time in his life, he had become "addicted" to the games he used to play. He played the games to the neglect of everything else in his life. He now believes that people can become addicted to computers as well and that the escapism he felt as a young boy is now being recreated via his use of the Internet-particularly through the playing of fantasy role-playing games (such as Dungeons and Dragons) and through the use of chat rooms. As Panos says:

I was $100 \%$ sure that you could only become addicted to a computer by playing games. I thought that it was impossible to become addicted to a computer by using it for professional purposes. Many years later I came to
England to study chemistry and I soon I realized that I couldn't do without computers. But this time it was not playing games. Gradually, I discovered the huge world of Internet and its many uses and applications. I used to go to the computer only to word process and print but now I am spending many hours every day exploring Internet, in addition to sending numerous E-mails and doing stuff that in fact (for entertainment) and to my opinion can ruin somebody's life."

Panos feels his whole life revolves around computers and that he feels comfortable being in this country when he is on the Internet. He claims that using the Internet excessively helps him cope with every day life as a university student. He spends an average 40-50 hours a week on the Internet but has no financial problems because he accesses the Internet for free from his university. His studies have suffered considerably as he spends so much time on the Internet, which leaves him little time to get on with his degree work.

\section{Commentary}

Panos, to some extent, appears to fit the stereotype of an internet addict in that he is a young male who appears to have little or no social life and little or no self-confidence. However, he appears to display only some the core components of addiction (salience, conflict, mood modification, and possibly tolerance), and, unlike the previous two cases, he does not deny he has a problem surrounding his Internet usage. The primary motivation for excessive Internet usage is to cope with the fact that he is in a foreign country in which he has very few friends. Panos very much uses the Internet for escapism and socializing.

It is interesting to note that Panos claimed he was once "addicted" to computer games. There have been a number of models putting forward a developmental account of person-machine relationships. ${ }^{12,13}$ It is perhaps unsurprising that a former computer game "addict" should use the Internet most excessively for the fantasy role-playing games. A fairly recent study of fantasy game players found that that the time spent on such games was "considerable" and that they were more introverted and more 
likely to "play with computers" and be computer game players than controls. ${ }^{14}$

\section{JODIE}

Demographic profile: 35-year-old Canadian female (unemployed); source of account: subject contacted author via an Internet discussion group; origin of data: written correspondence via the Internet.

Jodie spends at least 40 hours a week on the Internet. Her excessive usage is totally confined to IRC services. Jodie describes herself as "disabled, overweight and not at all attractive." She says that this makes no difference on the Internet because she gets to know others first in the Internet environment and that then when she meets them in "real life" later it does not matter. She says "I have met well over a dozen people in real life that I first met on IRC or in some other way through the Internet." She does not view her use of the Internet as an addiction although she does see it as a way of life.

Almost all of Jodie's relationships are Internet-based. The following extract is her account of the typical cycle of an Internet relationship.

I meet men through IRC and we start out the same as anyone else just chatting-where are you from? How old? Any kids? And then it evolves into exchanging pictures, phone calls and then an overwhelming desire to meet in real life. When I meet a guy, I usually decide to meet "as friends" and if there is more then that is fine. Even if there is nothing romantic I usually have a good time.

Jodie is now married to someone she met on the Internet but sees him very little because she lives in Alberta (Canada) and he lives in North Carolina (United States). They met on a camping holiday with other people she had met through the Internet. Jodie only meets with her husband at traditional vacation times (e.g., Christmas) and suffers verbal abuse from her mother about her marriage. Her mother thinks her daughter has lost her mind and is crazy for wanting to marry someone she feels that her daughter does not really know. Jodie says of her relationship:
Granted, our actual real life together time hasn't been much-however, I feel our time on the net (we speak for 3-4 hours every night) has given us MORE of a chance to really get to know each other ... . all we do is talk about our feelings, wants and needs, future desires etc.

Jodie feels her excessive Internet use is purely a function of the relationships in which she is involved and that it is no different from other people's use of the telephone. The emotional "highs" that she gains from using the Internet come from the social interaction rather than the Internet herself. She claims that she gets depressed and moody when she is not on IRC but again she says this is because it means she is on her own without it.

\section{Commentary}

Although Jodie appears to display some of the components of addiction (salience, mood modification, and withdrawal) she does not fit the young male stereotype. Similar to Jamie, she is very overweight and is explicit in explaining that she likes the Internet because no face-to-face communication takes place. Her primary motivation for using the Internet excessively was to socialise (also exacerbated by the fact that she is disabled) although this has now changed into the most accessible (cheapest) way to stay in touch with her partner. Jodie does not feel she has a problem in any way and feels that the excessiveness she displays on the Internet is totally vindicated by the situation she is in.

\section{DAVE}

Demographic profile: 32-year-old British male (employed); source of account: author contacted by subject's wife after reading an article about author's research on Internet addiction in a national newspaper; origin of data: written correspondence.

Dave ("a loveable happy man") had been married to his wife for 3 years and had lived with her for 7 years. They had a beautiful house, Dave had an excellent job, and they were both very happy-until the Internet en- 
tered Dave's life. The problem began when Dave changed jobs and had to spend more time at home-alone. As a result of this, Dave quickly became depressed and slightly withdrawn. As a result, he began spending time on the IRC whilst his wife was at work.

Within a couple of months of being at home, he became worse, could not sleep, and used the Internet long into the early hours of the morning. His wife claimed that Dave got "an incredible thrill from using (the Internet), as though filling a need within." He became angry and anxious, with "his whole body becoming twitchy when he was not on the Internet." He also suffered a loss of concentration and turned into someone that his wife did not know. Within 3 months of being at home, Dave's wife found out that he was using the Internet to live in a fantasy world-mainly with people in the United States. His wife claims "he became totally obsessed by it-not leaving his office for up to 5 days at a time, except to eat and sleep." The cost of Dave's Internet use was kept hidden from his wife but she found out that the "other woman" lived in Boston and that Dave would call her five or six times a day and talk to her for 3-4 hours on IRC.

Within 3 months of "working" from home, Dave had left his wife and walked out without a word. His wife did not know where Dave had gone until she found out he had gone to the United States to meet a woman who "understands" his fantasy world through the Internet. Dave proposed marriage to the American woman before he left the United Kingdomeven though he had never met her. His wife says that the Internet caused the destruction of their marriage, the loss of their house, and the loss of her husband.

Dave briefly returned home for 10 days but has now gone back to America "to live out his fantasy." As far as his wife knows, he is not now using the Internet. Dave now admits that his fantasy was not quite what he wanted, and that he is depressed and has begun to realise the damage of losing his job, his wife, and walking out on his family. Dave's wife speculates that men can emotionally communicate better through a computer than verbal communication. She says, "It seems to be so wide- spread now that people need to escape from every day life and intimacy via Internet."

\section{Commentary}

Although Dave is a male, he does not fit the Internet addict stereotype in that he is not a teenager or young. However, he does appear to fulfill most of the addiction components (at least while he was having his virtual affair) although the whole of his behaviour appears symptomatic and was completely motivated by his desire to interact constantly with a new "partner." Although there is no direct evidence, it appears that his Internet usage has now declined significantly or stopped now that he has finally met up with the woman with whom he was having a virtual affair.

\section{GENERAL DISCUSSION}

It is quite obvious that of the five cases, possibly only two of them (Gary and Jamie) were addicted according to the addiction components criteria. The excessive usage in the majority of cases was purely symptomatic and was where the Internet/computer was used to counteract other deficiencies (e.g., relationships, lack of friends, physical appearance, disability, coping, etc.). However, it is interesting that all of the case studies used the computer for social contact, with four of them using it for IRC services and the fifth one using the computer as an "electronic friend." As these cases show, text-based relationships can obviously be rewarding for some people and is an area for future research. It is perhaps also refreshing that in some circumstances, online relationships could be deemed to be psychologically healthy because they break down prejudices and that intimate relationships are not based on people's physical appearance.

The three young males were all only children who appeared socially isolated and had few social skills. These factors may or may not have had an influence in excessive computer use. However, the psychotherapist Rawlins ${ }^{15}$ has specifically reported some positive attributes through intensive Internet use. Rawlins sees many children who fit the criteria for Pervasive Developmental Delay or Atypical Autism. She 
reports that these children often "fit in hand and glove" with computer technology. They already have poor social relatedness and are rather isolated individuals. She argues that net use may actually augment and help their social interaction.

Another question to consider is whether the social pathologies in cyberspace are inevitable. Ajayi ${ }^{16}$ has reported that, where the Internet is concerned, what we are seeing is merely the continuation of a decades-long trend of people spending increasingly more time with technology than with humans. He argues that the shift away from family and peers to mass media technology as the primary socialization agents can be traced to the advent of radio in the 1930s, followed by television in the 1950s, and computer networks today. Ajayi further argues that, for many people, going online is a way of dealing with a society where people are becoming increasingly more isolated from one another.

One of the objectives of any future research should be to determine the object of the "addiction." Is it the process of typing? The medium of communication? Aspects of its specific style (no face-to-face, etc.)? The information that can be obtained (e.g., pornography)? Playing games? Talking to others (in chat rooms or on Internet Relay Chat)? Could it be that the Internet provides a medium for the "addiction" to flow to its object of unhealthy attachment (i.e., a secondary addiction to more pervasive primary problems)? The Internet could easily be the focus of obsessive and/or compulsive behaviours. One thing that may intensify this focus are the vast resources available on the Internet to feed or fuel other addictions or compulsions. For example, to a sex addict, the Internet could be a very dangerous medium. There is also the problem that the Internet consists of many different types of activity (e.g., E-mailing, information browsing, file transferring, socialising, role-game playing, etc.), and it could be the case (and probably is the case) that some of these activities (such as IRC or role-playing games) are more addictive than some other net activities.

Future research should establish why the internet is highly reinforcing for some people. Hammersly ${ }^{17}$ has speculated on a number of reasons that appear to fit with the case studies outlined in this article:

- It allows correspondence with people who share mutual interests.

- It puts people in touch with other people who they would otherwise never meet.

- The costs of communicating is low.

- There is a substantial "puzzle" element to using the internet, and many people find puzzling tasks reinforcing.

- People can download software toys, some of which are reinforcing.

- People can keep in touch with friends with minimal time and financial costs.

- It gives people feelings of status and modernity, which may bolster self-esteem. These are all commonplace reinforcers for humans.

- It allows people to be taken seriously and listened to.

- It allows people to present a "well-managed" persona, which may deviate in significant ways from one's every-day, faceto-face persona.

- It allows people to be boring about one's favourite hobby horse.

Finally, it is perhaps worth nothing that Griffiths ${ }^{5}$ speculated that the structural characteristics of the software might promote addictive tendencies. Structural characteristics (i.e., features that manufacturers design into their products) promote interactivity and, to some extent, define alternative realities for the user and allow them feelings of anonymity in features that may be very psychologically rewarding. For instance, determinants of the decision to engage in a particular activity not only include the person's biological and psychological constitution and the situational variables, but also the structural characteristics of the activity itself. As Griffiths ${ }^{18}$ points out, the structural characteristics of particular activities are responsible for reinforcement and may satisfy users' needs and may actually facilitate excessiveness. By identifying particular structural characteristics, it may be possible to see how (a) needs are identified, (b) information about the Internet is presented (or perhaps misrepresented), and (c) cognitions are influenced and 
distorted. (See Griffiths ${ }^{18}$ for an overview on structural characteristics.)

There is no doubt that Internet usage among the general population will start to increase over the next few years. If social pathologies do exist, than psychologists may well be the people who have to deal with the aftermath. This is certainly an area for development that should be of interest and concern to all those involved in clinical health issues.

\section{REFERENCES}

1. Griffiths, M.D. (1996). Internet "addiction": An issue for clinical psychology? Clinical Psychology Forum, 97:32-36.

2. Griffiths, M.D. (1997). Psychology of computer use: XLIII. Some comments on "Addictive use of the internet" by Young. Psychological Reports, 80:81-82.

3. Griffiths, M.D. (1995). Technological addictions. Clinical Psychology Forum, 76:14-19.

4. Griffiths, M.D. (1995). Adolescent gambling. London: Routledge.

5. Griffiths, M.D. (1995, April 7). Netties Anonymous. Times Higher Educational Supplement, p. 18.

6. Marks, I. (1990). Non-chemical (behaviourial) addictions. British Journal of Addiction, 85:1389-1394.

7. Griffiths, M.D. (1996). Nicotine, tobacco, and addiction. Nature, 384:18.

8. Hybels, S. (1995). Cited in "Terminal Addiction." Internet and Comms Today, p. 35.

9. Young, K. (1996). Psychology of computer use: XL. Addictive use of the internet: A case that breaks the stereotype. Psychological Reports, 79:899-902.

10. Selnow, G.W. (1984). Playing video games: The electornic friend. Journal of Communication, 34:148-156.
11. Wolfson, S. (1995, December). Star trek fan behaviour: "It's addiction Jim, but not as we know it." Paper presented at the British Psychological Society London Conference, Institute of Education, London.

12. Brown, R.I.F. (1989). Gaming, gambling, risk taking, addictions and a developmental model of a pathology of man-machine relationships. In: Klabber, J., Croowall, D., de Jong, H., and Scheper, W. (eds.). Simulation gaming. Oxford: Pergamon Press.

13. Griffiths, M.D. (1991). Amusement machine playing in childhood and adolescence: A comparative analysis of video games and fruit machines. Journal of Adolescence, 14:53-73.

14. Douse, N.A., and McManus, I.C. (1993). The personality of fantasy game players. British Journal of Psychology, 84:505-509.

15. Rawlins, C. (1995). Cited in "Terminal Addiction." Internet and Comms Today, p. 35.

16. Ajayi, A. (1995). Cited in Terminal Addiction. Internet and Comms Today, p. 36.

17. Hammersley, R. (1995). Personal e-mail communication to ADDICT-L discussion group.

18. Griffiths, M.D. (1993). Fruit machine gambling: The importance of structural characteristics. Journal of Gambling Studies, 9:133-152.

Address reprint requests to: Dr. Mark Griffiths Psychology Division Nottingham Trent University Burton Street Nottingham, NG1 4BU

E-mail: mark.griffiths@ntu.ac.uk 